\title{
Modelling Approaches for Minimally Gauged Sg Similajau, Bintulu
}

\author{
Darrien Yau Seng Mah ${ }^{\mathrm{a},}$, Ching Poon Hii ${ }^{\mathrm{b}}$ and Addy Kho ${ }^{\mathrm{b}}$ \\ ${ }^{a}$ Department of Civil Engineering, Faculty of Engineering, Universiti Malaysia Sarawak, \\ 94300 Kota Samarahan, Sarawak, Malaysia \\ ${ }^{b}$ Jurutera Adda Consulting Engineers, No 683, Lorong Song 1A, Off Jalan Song, 93350 \\ Kuching, Sarawak, Malaysia
}

\begin{abstract}
Minimally gauged river basins are common in Sarawak. Many river basins are lacking in hydrological monitoring mechanism mostly due to the vast land mass and complex river network, hence causing isolation of certain locations. This paper is describing the approaches to model $\mathrm{Sg}$ Similajau of Bintulu, Sarawak with little information to support sound analysis. A river model is developed to reconstruct missing flows of the river. In order to have reliable results, a short-term monitoring program is strongly suggested to collect data pertaining to river processes in the field. Pre-processing processes are demonstrated to obtain inflow data for upstream boundaries, tide/King Tide data for downstream boundary and a weir at Samalaju Water Intake for middle boundary. Particularly the weir, its presence convinces the verification of the river model. Post-processing on the impacts of the weir in flow patterns, in this case the water head produced by the weir and with such a head to flush out saltwater brought about by tides are demonstrated as ideal tool to test the model.
\end{abstract}

Keywords: broad crested weir, HEC-HMS, InfoWorks RS, river flow, salt transport.

\section{Introduction}

Sg Similajau covers a basin area of $\sim 636.5 \mathrm{~km}^{2}$ (see Figure 1). In terms of hydrological monitoring, only two stations are available. The only rainfall station in the basin, namely Kuala Similajau station is located $3 \mathrm{~km}$ from the estuary. The only water level station, namely Sg Similajau station is located $28 \mathrm{~km}$ from the estuary, a distance out of tidal influence. No rating curve is provided by the Sarawak Department of Irrigation and Drainage (DID). With only two monitoring stations that each with distinct measuring parameter, the river basin is classified as minimally gauged [1].

Previously, the river basin is scarcely populated and the major land use is agriculture land. Therefore, hydrological monitoring network is kept at minimal. With Samalaju Town being identified as an industrial park under the Sarawak Corridor of Renewable Energy (SCORE) initiative [2], physical development is underway. As such, hydrological analysis of the river basin is gaining importance to guide the planning of water resources for any intended growth [3]. For instances, water is demanded for industrial uses such as in the aluminum and downstream palm oil productions; water is required for daily living of workers/human population attended to the industries and so on.

This paper is therefore meant as a lesson learnt to solve the problem of minimally gauged $\mathrm{Sg}$ Similajau, in which critical hydrological data is lacking to support sound hydrological analysis [4],

* Corresponding author. Tel.: +082-583207; fax: +082-583409

E-mail address: ysmah@unimas.my

Manuscript History:

Received 20 March, 2017, Revised 10 September, 2017, Accepted 12 September, 2017, Published 30 September, 2017

e-ISSN: 2289-7771

Copyright (C) 2017 JASPE

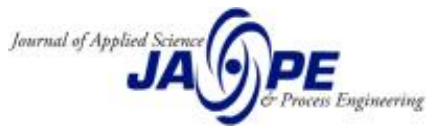


[5]. It also serves as a guideline for any future development in the same basin, as well as to be an excellent case study for other minimally gauged river basins.

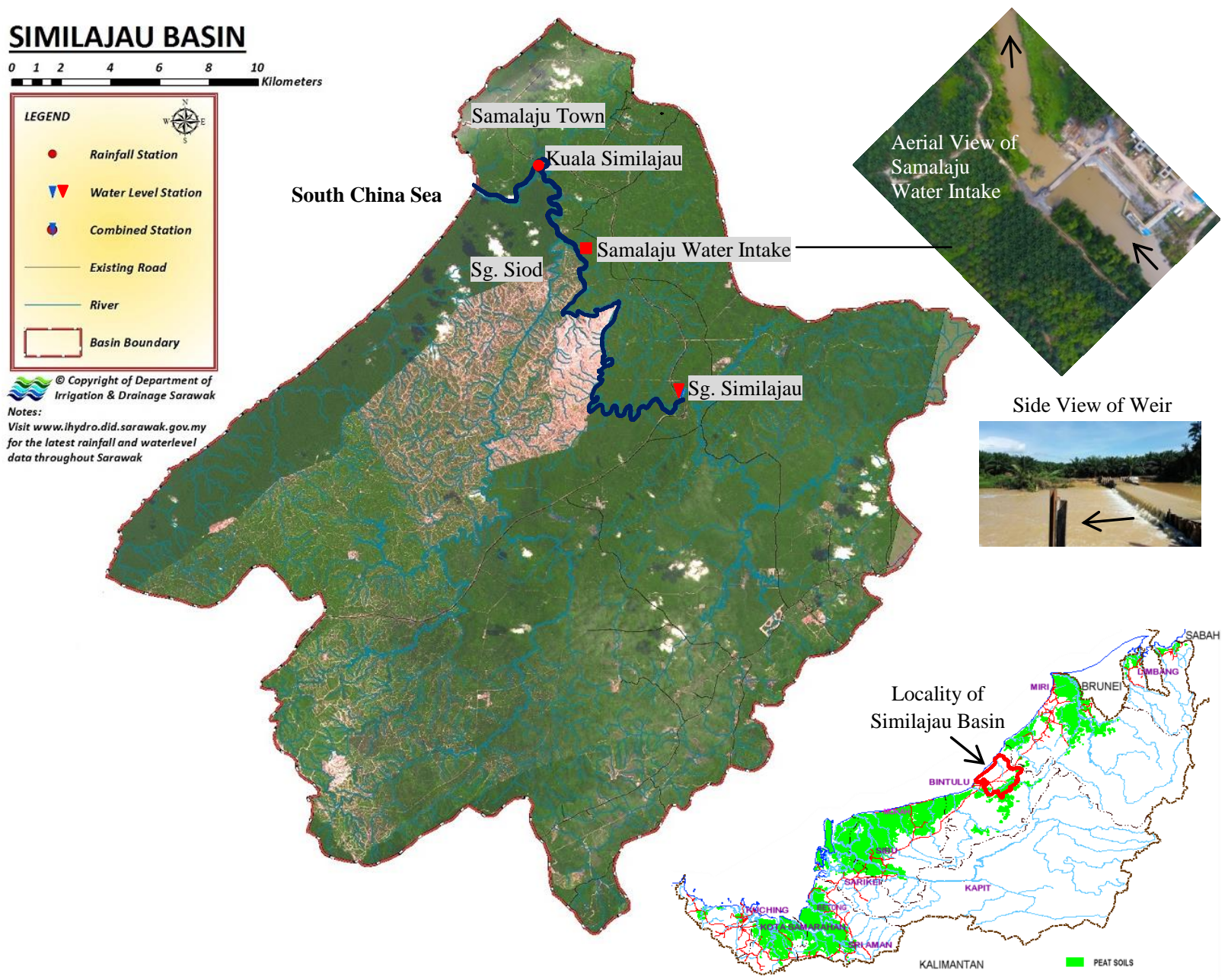

Figure 1. Sg Similajau Basin and Topography Map (http://www.did.sarawak.gov.my).

\section{Descriptions of River Basin}

The river basin under study consists of two principal tributaries, namely $\mathrm{Sg}$ Siod and $\mathrm{Sg}$ Similajau that drain the southwestern and southeastern catchments respectively. These two rivers confluence at a point $8 \mathrm{~km}$ from the estuary. Water level records are available only on Sg Similajau; and no water level record for Sg Siod. Apparently, river flow data is absent for both rivers. Rainfall station is at the fringe of Samalaju town but the closeness to the coastal line indicating a representation of coastal weather. Inland weather data is absent. Samalaju Water Intake and a weir across Sg Similajau are located about $10 \mathrm{~km}$ from the estuary.

\section{Approaches to River Modelling}

\subsection{River Model}

The missing flow data of the Sg Similajau could be reconstructed using a river model [6]. River model mimics the flow conveyance of a river, which is the volume of water over time when travels from one point to another. Profiles of the river channel were necessary to estimate the river flows. To 
represent well the river channel of Sg Similajau, sixteen (16) river cross sections were surveyed in September 2016 to form the river network (Figure 2). Longitudinal section profile of the selected $28 \mathrm{~km}$ river reaches is presented in Figure 3. Software being utilized is InfoWorks River Simulation (RS), in which it combines water flow engine with spatial technology.

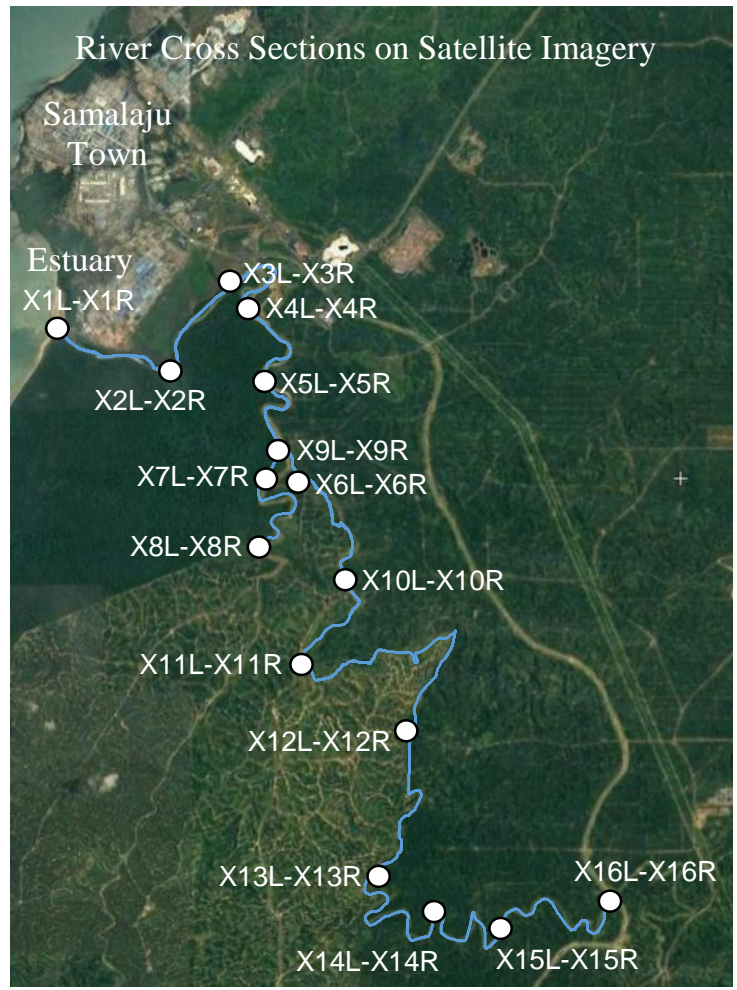

\section{River Network associated with Boundary Conditions}

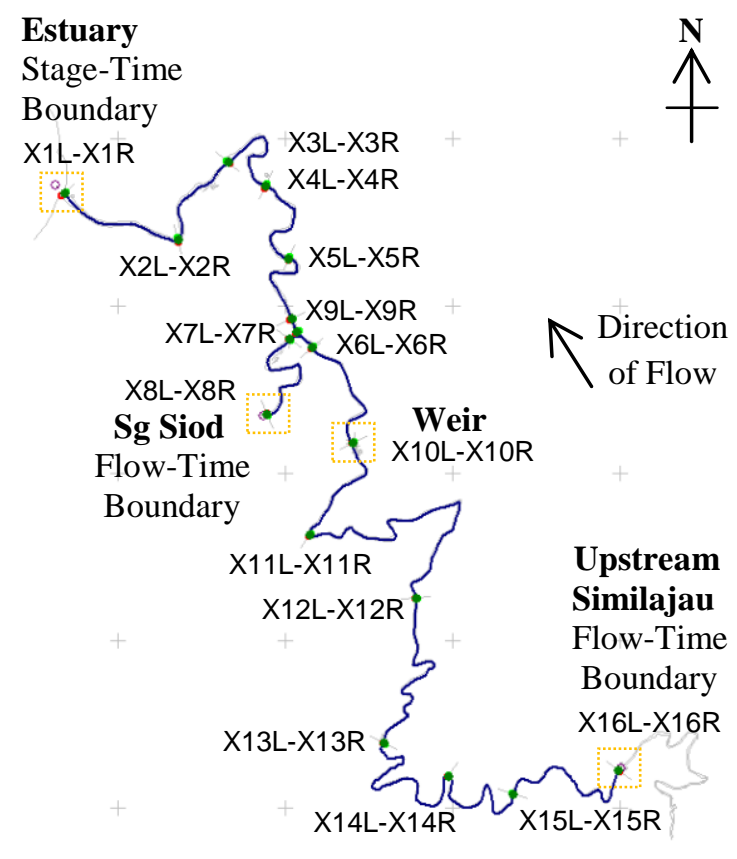

Figure 2. Sg Similajau Cross Sections, River Network and Boundary Conditions.

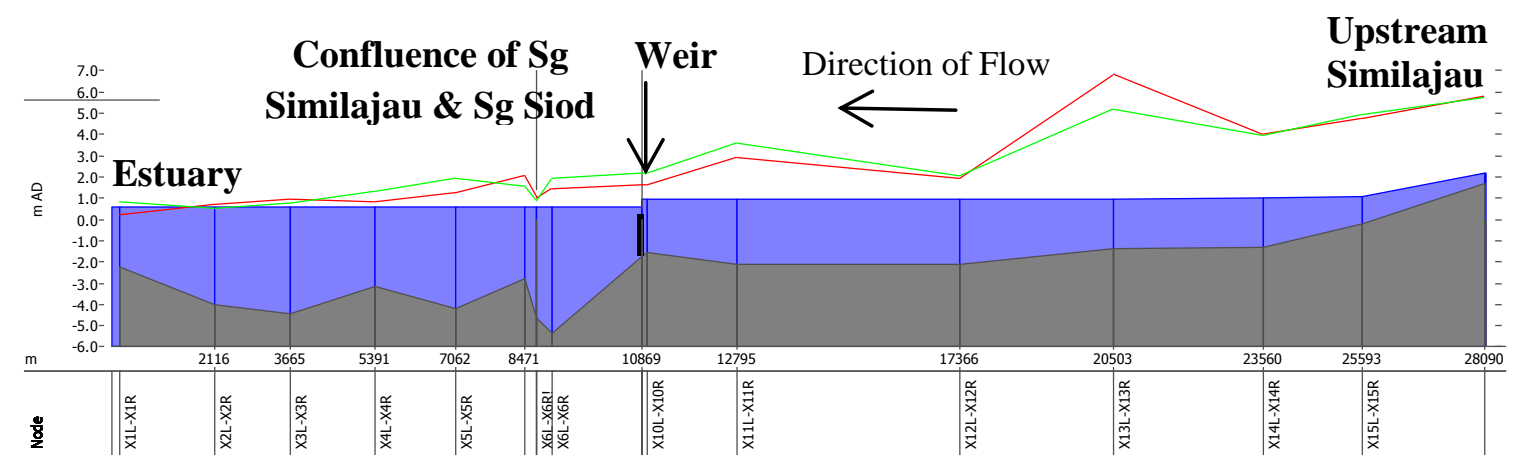

[Legend: Green line = left bank; Red line = right bank; Blue line = water level; Grey line = river bed]

Figure 3. Longitudinal Section of Sg Similajau.

\subsection{Rainfall Runoff Simulation}

As mentioned before, there is only one rainfall station in Sg Similajau basin that hardly representing the whole river basin. Rainfall data from neighbouring river basins could be used together with data of Kuala Similajau rainfall station to generate average rainfall patterns for Similajau Basin. As such, synthetic river flow hydrographs of Sg Siod and Upstream Similajau could be derived using HEC-HMS by the principle of catchment characteristics in rainfall-runoff relationships [7]. 
Flow engine in InfoWorks RS could compute flow by solving the St Venant equations. In order to meet the numerical computation, two (2) Flow-Time boundaries are defined for Sg Siod and Upstream Similajau sub-basins. Stage-Time boundary is selected to represent the tidal fluctuations at the estuary. A schematic of river flow approach is presented in Figure 4.

Water level data recorded at the Sg Similajau Station could be used to verify the synthetic river flows of Upstream Similajau sub-basin. By assuming Upstream Similajau and Sg Siod sub-basins are homogenous for being next to each other, catchment characteristics of Upstream Similajau are transposed to $\mathrm{Sg}$ Siod. With the computed average rainfall, rainfall-runoff processes could be simulated by HEC-HMS for both sub-basins. The synthetic flows are then inserted into the river model.

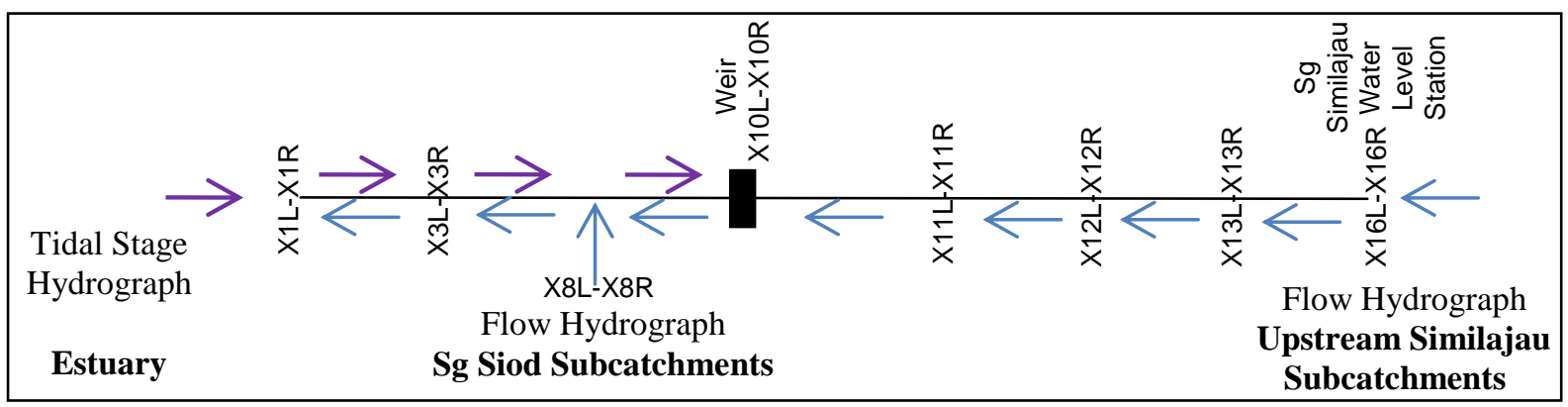

Figure 4. Approach to Flow Conveyance of Sg Similajau.

\subsection{Verification of River Model}

Although rainfall runoff data could be computed, these data should be calibrated or verified so that they represent well the river processes in the field. Therefore, a short-term monitoring is usually helpful to gather infield data for the mentioned purposes. A three-day field survey was carried out in conjunction with a King Tide event on 11-14 January 2017. The fieldworks include:

1) Continuous tide data near to estuary were recorded using water level sensor and data logger;

2) Continuous water level data at Samalaju Water Intake were recorded using water level sensor and data logger;

3) Continuous flow data at Upstream Similajau were taken using flowmeter and data logger; and

4) Salinity data at Samalaju Water Intake were recorded by sampling the river water at 3-hour interval throughout the three-day ordeal.

As such, river modelling of the three-day King Tide event with salt transport could be carried out with InfoWorks RS using the principles of St Venant, advection and diffusion [8]. Advection is dependent directly on the flow and geometry of the river channel. Diffusion represents the tidal mixing processes. In InfoWorks RS, longitudinal, lateral and vertical mixing processes are represented as a single mixing process. A schematic of salt transport approach is presented in Figure 5.

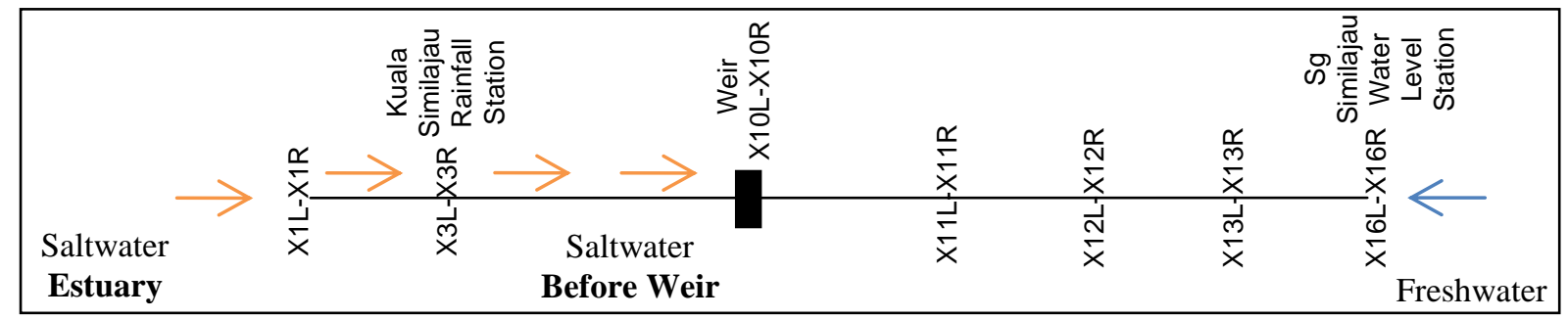

Figure 5. Approach to Salt Transport of Sg Similajau. 


\subsection{Significant of Weir}

Synthetic flows of Upstream Similajau and Sg Siod are the beginners to be fed to InfoWorks RS river model. It shall end with the collected tidal data coincided with the King Tide of 11-14 January 2017. The river model needs some data in the middle reaches to convince its reliability. If the river is free flowing, it could be a challenge to provide solid data due to spatial and temporal variability along a river are naturally huge.

With a weir in placed, Sg Similajau has been transformed to a regulated river. The nature of fixed geometry of a weir allows river flow through the weir to be predictable [9]. Also, the accessibility to the water intake and weir enables the dispatch of fieldwork team to collect necessary data at that point.

\section{Results and Discussion}

Results of modelling Sg Similajau based on the mentioned King Tide event are discussed below.

\subsection{Conveyance of River Flow}

Flow hydrograph of Upstream Similajau for January 11-14, 2017 was routed $17 \mathrm{~km}$ down the river to reach the weir at Samalaju Water Intake. Flowing over the weir at a crest height of $1.3 \mathrm{~m}$ above datum (AD), it generates a range of $1.38-1.51 \mathrm{~m}$ backwater levels $100 \mathrm{~m}$ before the weir (Figure 6).

Comparing the measured and modelled water levels before the weir, the matching is acceptable $\left(\mathrm{R}^{2}=0.8\right)$. It means the river model simulated the upper stretch of Sg Similajau well. The output also provided the roughness values of the river system, namely Manning's n of 0.015 for the sandy clay river channel and 0.4 for the vegetation along the riverbanks.

On another note, the measured water level before the weir could be compared with the associated measured tide level at Samalaju town (Figure 7). The time series indicated a general water level of $1.5 \mathrm{~m}$ AD before the weir.

Overtopping of the weir by King Tide was indicated during late evenings of January $11^{\text {th }}$ and $12^{\text {th }}, 2017$ (see the circles in Figure 7). The tide levels were higher than the weir crest and backwater level before the weir for short period of times.

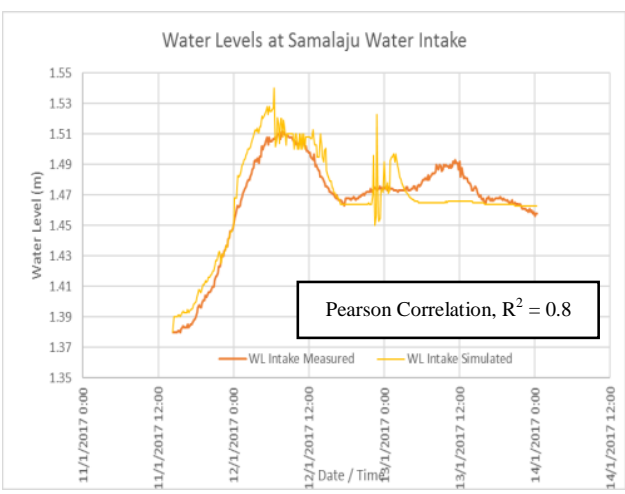

Figure 6. Comparison of Measured and Modelled Water Levels at Samalaju Water Intake.

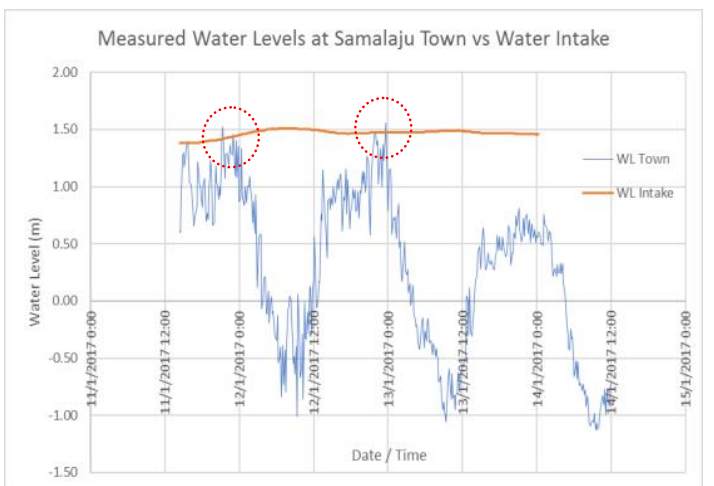

Figure 7. Comparison of Water Levels for Samalaju Water Intake and Samalaju Town. 


\subsection{Salt Transport}

Estuary of Sg Similajau was injected with $30 \mathrm{~g} / \mathrm{L}$ of salinity. This concentration of salt was dispersed by the King Tide towards upstream (with dispersion coefficient in $\mathrm{D}_{0}=30 \mathrm{~m}^{2} / \mathrm{s}, \mathrm{D}_{1}=250 \mathrm{~m}^{2} / \mathrm{s}, \mathrm{D}_{2}=0$ ).

The measured and modelled profiles of salinity at Downstream Weir are found to have an acceptable fit $\left(\mathrm{R}^{2}=0.7\right)$ (Figure 8). The model is therefore reasonable in simulating salt transport. It also means the river model simulated the lower stretch of $\mathrm{Sg}$ Similajau well.

At a point at Samalaju town (N03 $311^{\prime} 27.4$ "' E113 19 '45.2"), the fieldwork team had recorded a salinity of $7.8 \mathrm{~g} / \mathrm{L}$ at $11 \mathrm{am}$ on $12^{\text {th }}$ January 2017 . The model simulated a salinity of $7 \mathrm{~g} / \mathrm{L}$ (see the dotted line in Figure 9), which is close to the observed value.

It should be noted that the inflow of Sg Siod has not been verified. With the verified salt profile at Samalaju town, it also indicates the flow of Sg Siod is reasonable. This is because flow volume of this tributary could have impacted the salinity downstream, meaning high flow may dilute the salt further and vice versa for low flow.

On another note, the fieldwork team had observed a consistent $0.05 \mathrm{~g} / \mathrm{L}$ of salt at and before the weir (Figure 10). River model simulated similar salt profiles before the weir (Figure 11). It further estimated the extent of saline intrusion to $17-20 \mathrm{~km}$ from estuary / 7-10km upstream of weir.

The combination of weir crest height at $1.3 \mathrm{~m}$ $\mathrm{AD}$ and the water head created above and before the weir is adequate to push off salt. It also suggests that with water abstraction and low flow event in the future may reduce the mentioned water head to cause an extent of saline intrusion upstream of weir that yet to be determined.

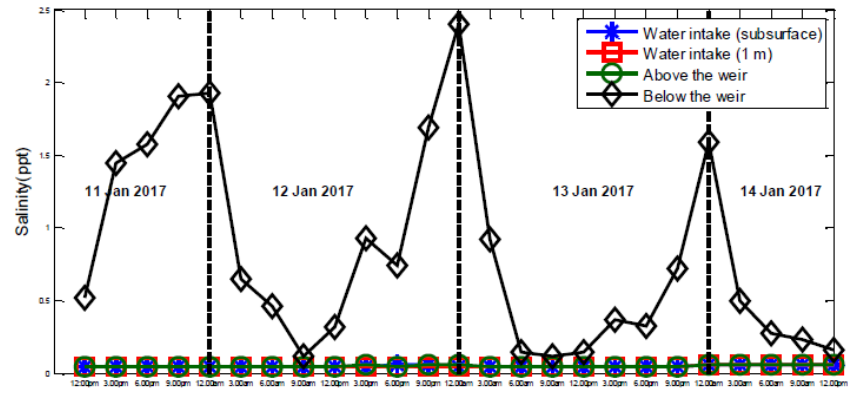

Figure 10. Observed Salt Profiles.

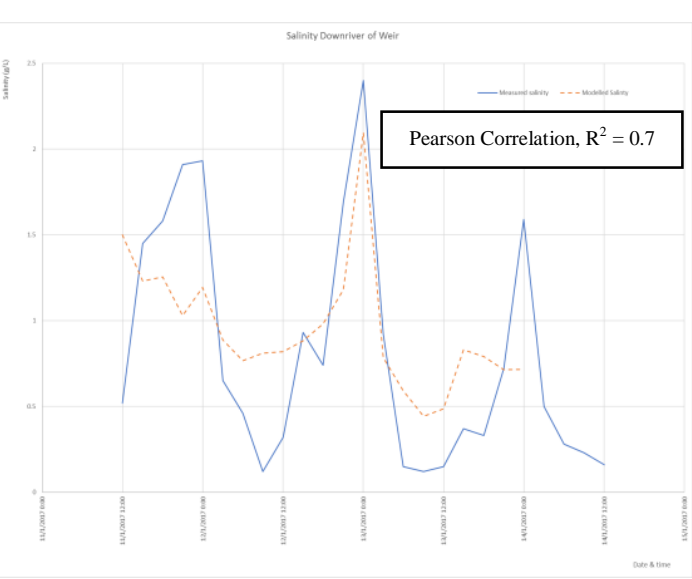

Figure 8. Comparison of Measured and Modelled Salinity Profiles at Downstream Weir.

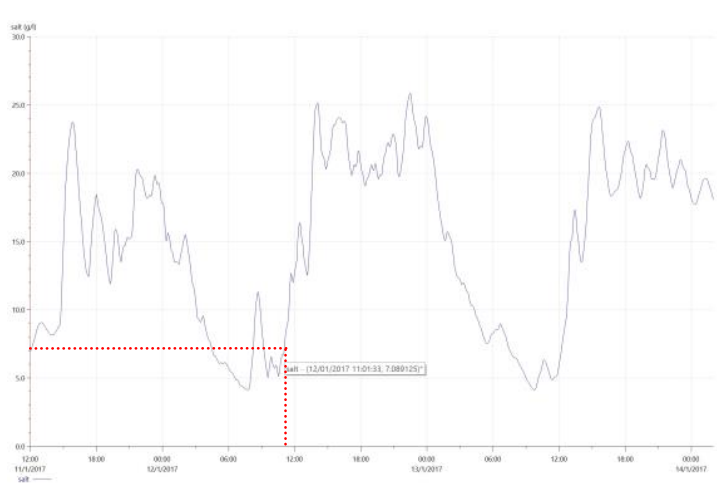

Figure 9. Simulated Salt Profiles at Samalaju Town (X3L-X3R).

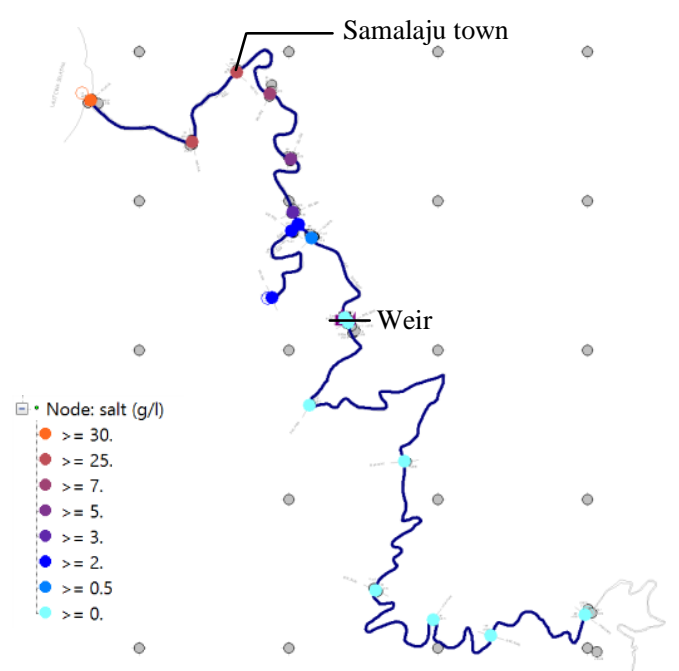

Figure 11. Simulated Salt Profiles along Sg Similajau. 


\section{Conclusions}

This paper describes how to deal with the minimally gauged Sg Similajau in terms of:

a) In the absence of sufficient rainfall data for the river basin, rainfall data of neighbouring river basins could be integrated to get average rainfall, which in turn the average rainfall could be employed to compute synthetic flow data;

b) In the absence of river flow data, a river model with well-representative river channel could be used to rout flows along the river;

c) Synthetic flows and routed flows could be verified with a short-termed monitoring of the river;

d) For tidally influenced river like $\mathrm{Sg}$ Similajau, salinity profiles could be collected and modelled to support river model verification; and

e) A permanent manmade structure like a weir adds a consistent flow pattern over the structure that could be used as another means of river model verification.

The approaches presented here have demonstrated to produce reliable modelling results based on the 11-14 January 2017 King Tide event. The developed river model is therefore concluded to be able to mimic the real-world river processes, and to assist water resources planning of the river basin.

\section{Acknowledgement}

Authors would like to thank the supports given by the Jabatan Bekalan Air Luar Bandar (JBALB) of Sarawak.

\section{References}

[1] World Meteorological Organization (WMO). (2008). Guide to Meteorological Instruments and Methods of Observation, WMO-No.8, $7^{\text {th }}$ Edition, ISBN 978-92-63-10008-5, WMO, Geneva, Switzerland.

[2] Sarawak State Planning Unit (SPU). (2016). Sarawak Corridor of Renewable Energy, Powering the Future, Seminar on Investment Opportunities in the Resource Based Industries, Pullman Kuching, Sarawak, 18 April 2016.

[3] Jacobs, K., Lebel, L., Buizer, J., Addams, L., Matson, P., McCullough, E., Garden, P., Saliba, G. and Finan, T. (2016). Linking Knowledge with Action in the Pursuit of Sustainable Water-Resources Management, Proceedings of the National Academy of Sciences, Vol. 113, No. 17, 4591-4596.

[4] Liu, S., Xie, Z. and Zeng, Y. (2016). Discharge Estimation for an Ungauged Inland River in an Arid Area Related to Anthropogenic Activities: A Case Study of Heihe River Basin, Northwestern China. Advances in Meteorology, Vol. 2016, Article ID 6716501, DOI:10.1155/2016/6716501.

[5] D’Ambrosio, E., De Girolamo, A.M., Barca, E., Ielpo, P. and Rulli, M.C. (2017). Characterising the Hydrological Regime of an Ungauged Temporary River System: A Case Study. Environmental Science and Pollution Research, Vol. 24, No. 16, 13950-13966, DOI: 10.1007/s11356-016-7169-0.

[6] Atieh, M., Taylor, G., Sattar, A.M. and Gharabaghi, B. (2016). Prediction of Flow Duration Curves for Ungauged Basins. Journal of Hydrology, Vol. 545, 383-394, DOI:10.1016/j.jhydrol.2016.12.048.

[7] Sok, K. and Oeurng, C. (2016). Application of HEC-HMS Model to Assess Streamflow and Water Resources Availability in Stung Sangker Catchment of Mekong' Tonle Sap Lake Basin in Cambodia. Preprint 2016, 2016120136, DOI:10.20944/preprints201612.0136.v1.

[8] Zhu, Z., Oberg, N., Morales, V.M., Quijano, J.C., Landry, B.J. and Garcia, M.H. (2016). Integrated Urban Hydrologic and Hydraulic Modelling in Chicago, Illinois. Environmental Modelling \& Software, Vol. 77, 63-70, DOI:10.1016/j.envsoft.2015.11.014.

[9] Saberi, A. and Weaver, R.J. (2016). Simulating Tidal Flushing Response to the Construction of a LowCrested Weir Connecting Port Canaveral to the Banana River, Florida. Journal of Waterway, Port, Coastal, and Ocean Engineering, Vol. 142, No. 4, 05016002, DOI:10.1061/(ASCE)WW.1943-5460.0000337. 